\title{
Diet quality indices in relation to metabolic syndrome in an Indigenous Cree (Eeyouch) population in northern Québec, Canada
}

\author{
Mathilde Lavigne-Robichaud ${ }^{1,2}$, Jean-Claude Moubarac ${ }^{3}$, Stéfanie Lantagne-Lopez ${ }^{1,2}$, \\ Louise Johnson-Down ${ }^{4}$, Malek Batal ${ }^{3}$, Elhadji A Laouan Sidi ${ }^{2}$ and Michel Lucas ${ }^{1,2, *}$ \\ 'Department of Social \& Preventive Medicine, Laval University, Québec, QC, Canada: ${ }^{2}$ Population Health and \\ Optimal Health Practices Research Unit, CHU de Québec - Laval University, St-Sacrement Hospital, 1050 Ste-Foy \\ Street, Office JS1-24, Québec, QC, Canada, G1S 4L8: ${ }^{3}$ TRANSNUT, Department of Nutrition, Faculty of Medicine, \\ University of Montréal, Montréal, QC, Canada: ${ }^{4}$ Centre for Indigenous Peoples' Nutrition and Environment, School \\ of Dietetics and Human Nutrition, McGill University, Montréal, QC, Canada
}

Submitted 23 October 2016: Final revision received 3 April 2017: Accepted 8 May 2017: First published online 7 July 2017

\begin{abstract}
Objective: To assess associations between three diet quality indices and metabolic syndrome (MetS) in the Cree (Eeyouch) of northern Québec, Canada, as well as to evaluate their pertinence in this Indigenous context.

Design: The alternative-Healthy Eating Index 2010 (aHEI-2010), the Food Quality Score (FQS) and the contribution of ultra-processed products (UPP) to total daily dietary energy intake using the NOVA classification were calculated from $24 \mathrm{~h}$ food recalls. MetS was determined with the latest harmonized definition. Logistic regressions assessed the relationship between quintiles of dietary quality scores with MetS and its components.

Setting: Study sample from the 2005-2009 cross-sectional Nituuchischaayibititaau Aschii Environment-and-Health Study.

Subjects: Eeyouch ( $n$ 811) from seven James Bay communities ( $\geq 18$ years old). Results: MetS prevalence was 56.6\% with 95.4\% abdominal adiposity, 50.1\% elevated fasting plasma glucose, $43.4 \%$ hypertension, $38.6 \%$ elevated TAG and $44.5 \%$ reduced HDL cholesterol. Comparing highest and lowest quintiles of scores, adjusted OR (95\% CI) of MetS was $0.70(0.39,1.08 ; P$-trend $=0.05)$ for aHEI-2010, $1.06(0.63,1.76 ; P$-trend =0.87) for FQS and 1.90 (1.14, 3.17; $P$-trend $=0.04)$ for the contribution of UPP to total daily dietary energy intake. Conclusions: Although diet quality indices have been associated with cardiometabolic risk, only the dietary intake of UPP was significantly associated with MetS in the Eeyouch. Indices tailored to the food environment of northern communities are essential to further understand the impact of diet quality in this context.
\end{abstract}

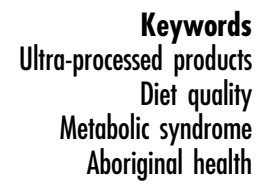

Recently, new multidimensional tools of global diet quality have been developed to assess diet as a whole rather than based on individual nutrients ${ }^{(1)}$. The alternative Health Eating Index 2010 (aHEI-2010) $^{(2)}$ and the Food Quality Score (FQS) ${ }^{(3)}$ measure the overall diet quality, whereas the NOVA classification allows measurement of the contribution of ultra-processed products (UPP) to total daily dietary energy intake ${ }^{(4)}$. Based on epidemiological studies, when compared with diet patterns based on whole grains, vegetables and fruits, low diet quality scores contribute to higher chronic disease risks ${ }^{(5-7)}$ and promote weight gain ${ }^{(8-10)}$. Consumption of UPP was associated with higher incidence of obesity ${ }^{(11)}$ and hypertension ( $\mathrm{R}$ de $\mathrm{D}$ Mendonça, unpublished results) in a prospective cohort of Spanish middle-aged adult university graduates.

Indigenous populations suffer from a greater disease burden, including obesity, abdominal adiposity, type 2 diabetes mellitus (T2DM) and metabolic syndrome (MetS) $^{(12,13)}$. The prevalence of MetS, which is a cluster of risk factors of T2DM and CVD, ranges from 21 to $40 \%$ among Canadian Indigenous communities ${ }^{(14,15)}$. The ageadjusted prevalence of T2DM among First Nations is 17.2 (95\% CI $16 \cdot 5,19 \cdot 0) \%$, three- to fivefold higher than in the general Canadian population ${ }^{(16-18)}$.

The Eeyouch from James Bay, northern Québec, are no exception. The crude prevalence of T2DM in this 
population was estimated at $17.3 \%$ in $2005-2009^{(19)}$. The prevalence of overweight among Eeyouch adults is $91.6 \%$, including $70.6 \%$ of obesity ${ }^{(20)}$. The loss of traditional practices, limited access to certain fresh and minimally processed foods as well as nutritional transition have been identified as contributing factors ${ }^{(21,22)}$. The local foods - gathered fish, game (moose, caribou, bear, etc.), birds (geese and ducks) and wild plants and fruits - have been replaced with a Westernized diet rich in UPP known to be high in energy density, free sugars, saturated fat and sodium, and low in protein, fibre and micronutrients ${ }^{(23-25)}$. The diet of Eeyouch has been associated with obesity ${ }^{(26,27)}$ and insulin resistance ${ }^{(22)}$.

Although studies have observed a relationship between diet quality and several chronic diseases ${ }^{(1,28)}$, the information provided by three diet quality assessment tools the aHEI-2010, FQS and the contribution of UPP to total daily dietary energy intake using the NOVA classification has never been evaluated among Indigenous peoples, notably the Eeyouch communities from Québec.

Therefore the primary objective of the present study was to evaluate the association between diet quality and MetS in adult Eeyouch of Eastern James Bay in Québec, using three methods: the aHEI-2010, FQS and the contribution of UPP to total daily dietary energy intake using the NOVA classification. The secondary objective was to assess the pertinence of these diet quality indices in an Eeyouch context.

\section{Methods}

\section{Study population}

The Eeyouch from seven communities of Eastern James Bay were invited to participate in the cross-sectional Nituuchischaayibititaau Aschii Environment-and-Health Study between 2005 and 2009. All Eeyouch adults with the exception of pregnant and nursing women were eligible. Details of the age-stratified and random recruitment have been provided elsewhere ${ }^{(19,21,22)}$. Participation rate ranged from 28.5 to $60.1 \%$ depending on the community. A total of 881 Eeyouch adults, aged 18 years or above, were surveyed. Complete data were available for 811 participants who were included in the present analysis.

\section{Dietary assessment}

Interviews were conducted, in English or Cree, by the trained community research personnel. A $24 \mathrm{~h}$ recall was conducted, between the months of June and September of 2005-2009, according to a five-step multiple-pass method $^{(29)}$ using three-dimensional food models to increase accuracy of assessed intakes.

In order to assess diet quality, two scores were calculated as well as the contribution of UPP to total daily dietary energy intake using the NOVA classification (Table 1). The aHEI-2010 is based on a combination of eleven nutrients or foods previously associated with chronic diseases and mortality in epidemiological studies $^{(2)}$. The total aHEI-2010 score ranged from 0 (worst) to 110 (best). Higher scores (maximum 10) were attributed for higher intakes of vegetables, fruits, whole grains, nuts/ legumes, long-chain $n$ - 3 fatty acids, PUFA and moderate alcohol consumption. Consumption of sugar-sweetened beverages/juices, red and processed meats, trans-fatty acids as well as sodium led to lower scores (minimum 0).

The FQS is based solely on the consumption frequency of fourteen foods. Six of these (vegetable, fruits, whole grain, yoghurt, coffee and nuts) have been strongly associated with lower risk of coronary artery disease and weight gain ${ }^{(3)}$. Intakes of these foods were grouped into quintiles and assigned a score ranging from 1 to 5 . Reversed quintile ranking score, from 5 to 1 , was attributed to the remaining eight foods (red and processed meats, potatoes, potato chips, refined grains, sugar-sweetened beverages, dessert and fried foods) known to increase the risk of coronary artery disease and weight gain. The sum of quintiles for all fourteen foods provides an overall score ranging from 14 (worst) to 70 (optimal).

The NOVA classification allowed us to classify all foods from the $24 \mathrm{~h}$ recall by processing type. The NOVA classification is based on the extent and purpose of food processing and categorizes foods and drinks into four main groups: Group 1, unprocessed or minimally processed (i.e. fresh fruits and vegetables, roots, legumes, eggs, etc.); Group 2, culinary ingredients (i.e. oils, sugar, salt, etc.); Group 3, processed products (i.e. canned or bottled vegetables, fruits and legumes, salted, sugared or cured meat, fish or nuts, etc.); and Group 4, ultraprocessed products (i.e. carbonated drinks, salty or sweet snacks, commercial breads, cereals or energy bars, etc.). Using NOVA, we measured the contribution of UPP to total daily dietary energy intake, which was associated with poor diet quality and adverse health outcomes ${ }^{(4)}$.

\section{Sociodemographic characteristics}

Participants completed questionnaires, with the bilingual community interviewers, providing sociodemographic information such as age, sex, smoking status, usual alcohol consumption and area of residence.

\section{Metabolic syndrome}

The presence of MetS among adult Cree was assessed according to latest harmonized definition ${ }^{(30)}$ (Table 2). Trained research nurses measured waist circumference (WC; in centimetres) upon exhalation with the measuring tape between the last floating rib and the iliac crest $^{(31)}$. In the absence of specific recommendations for North American Indigenous populations, it has been proposed that the South Asian thresholds are the most appropriate ${ }^{(15,32,33)}$. Thus WC was interpreted as a measure of central obesity according to the specific ethnic threshold of $\geq 90 \mathrm{~cm}$ for men and $\geq 80 \mathrm{~cm}$ for women to align with the current recommendations ${ }^{(30,33,34)}$. Three measures of blood pressure were taken by the research nurses according to the 
Table 1 The aHEI-2010, FQS scoring method and NOVA foods classification

\begin{tabular}{|c|c|c|}
\hline aHEI-2010 & Minimum score $(0)$ & Maximum score (10) \\
\hline Vegetables (servings/d) & 0 & $\geq 5$ \\
\hline Fruit (servings/d) & 0 & $\geq 5$ \\
\hline \multicolumn{3}{|l|}{ Whole grains $(\mathrm{g} / \mathrm{d})$} \\
\hline Women & 0 & 75 \\
\hline Men & 0 & 90 \\
\hline Nuts and legumes (servings/d) & 0 & $\geq 1$ \\
\hline LC $n-3$ fatty acids (EPA + DHA; mg/d) & 0 & $2 \overline{50}$ \\
\hline PUFA (\%E) & $\leq 2$ & $\geq 10$ \\
\hline SSB and fruit juice (servings/d) & $\geq 1$ & 0 \\
\hline Red/processed meat (servings/d) & $\geq 1.5$ & 0 \\
\hline Trans-fatty acids (\%E) & $\geq 4$ & $\leq 0.5$ \\
\hline Sodium & Highest decile & Lowest decile \\
\hline \multicolumn{3}{|l|}{ Alcohol (drinks/d) } \\
\hline Women & $\geq 2.5$ & $0.5-1.5$ \\
\hline Men & $\geq 3.5$ & $0.5-2.0$ \\
\hline Total score & 0 & 110 \\
\hline FQS & Minimum score (1) & Maximum score (5) \\
\hline Vegetables, fruit, whole grains, nuts, yoghurt, coffee & Lowest quintile & Highest quintile \\
\hline $\begin{array}{l}\text { SSB, red meats, processed meats, refined grains, deserts/ice cream, } \\
\text { potatoes, potato chips, fried foods away from home }\end{array}$ & Highest quintile & Lowest quintile \\
\hline Total score & 14 & 70 \\
\hline NOVA & \multicolumn{2}{|c|}{ Contribution (\%) to total daily dietary energy intake } \\
\hline Group 1: Minimally or unprocessed & \multirow{4}{*}{\multicolumn{2}{|c|}{$\begin{array}{l}\text { Meat, poultry \& fish, milk \& plain yoghurt, fruits, vegetables, eggs, } \\
\text { roots \& tubers, etc. } \\
\text { Fat (butter, oil, cream), table sugar, starches, etc. } \\
\text { Cheese, canned goods, salted or oil-roasted nuts, processed peanut } \\
\text { butter, etc. } \\
\text { Commercial breads, SSB and juice, candies \& ice cream, breakfast } \\
\text { cereals, margarine, processed meats, etc. }\end{array}$}} \\
\hline Group 2: Culinary ingredients & & \\
\hline Group 3: Processed products & & \\
\hline Group 4: Ultra-processed products & & \\
\hline
\end{tabular}

aHEI-2010, alternative Healthy Eating Index 2010; LC, long chain; FQS, Food Quality Score; \%E, percentage of energy; SSB, sugar-sweetened beverages.

Table 2 Harmonized metabolic syndrome definition

\begin{tabular}{|c|c|}
\hline Metabolic syndrome & Any three criteria \\
\hline Central obesity & $\begin{array}{l}\text { Waist circumference (South Asian) } \\
\text { Men: } \geq 90 \mathrm{~cm} \\
\text { Women: } \geq 80 \mathrm{~cm}\end{array}$ \\
\hline $\mathrm{TAG}^{*}$ & $\geq 1.70 \mathrm{mmol} / \mathrm{l}$ \\
\hline HDL cholesterol* & $\begin{array}{l}\text { Men: } \leq 1.03 \mathrm{mmol} / \mathrm{l} \\
\text { Women: } \leq 1.29 \mathrm{mmol} / \mathrm{l}\end{array}$ \\
\hline $\begin{array}{l}\text { Fasting plasma glucose } \\
\text { Hypertension* }\end{array}$ & $\begin{array}{l}\geq 5.6 \mathrm{mmol} / \mathrm{l} \\
\geq 130 / 85 \mathrm{mmHg}\end{array}$ \\
\hline
\end{tabular}

${ }^{*}$ Condition is considered present if patient is receiving specific treatment for this condition or in presence of a previous diagnosis.

current Canadian Hypertension Education Program recommendation ${ }^{(35)}$. The average of two measures was then calculated. Hypertension was considered if systolic blood pressure was $130 \mathrm{mmHg}$ or above, or if diastolic blood pressure was $85 \mathrm{mmHg}$ or above ${ }^{(34)}$.

Also, blood samples for the measurement of a number of metabolites were taken. Participants of the Nituuchischaayihititaau Aschii were instructed to fast overnight before blood samples were taken. The methods for laboratory measurements, including fasting plasma glucose (FPG) and fasting lipids, are described elsewhere ${ }^{(22)}$. The following thresholds for TAG, HDL cholesterol (HDL-C) and FPG were used: TAG $>1.7 \mathrm{mmol} / \mathrm{l}$; HDL-C $<1.03 \mathrm{mmol} / \mathrm{l}$ in men and $<1.29 \mathrm{mmol} / \mathrm{l}$ in women; and FPG $>5.6 \mathrm{mmol} / \mathrm{l}$.
To be categorized as having MetS, participants must present any three risk factors among central obesity, hypertension, elevated TAG, reduced HDL-C and elevated FPG ${ }^{(30)}$.

\section{Statistical analysis}

First, normality was assessed with the Shapiro-Wilk test and non-Gaussian distributions underwent a logarithmic transformation. Descriptive statistics of logarithmic transformation were calculated with geometric means and presented with a $95 \%$ CI. Categorical values are given by proportions. The aHEI-2010 scores (range 0-110) and the FQS (range 14-70) were classified into quintiles ${ }^{(2,3)}$. The contribution (0-100\%) of UPP to total daily dietary energy intake was also classified into quintiles.

The aHEI-2010 and FQS measure the positive impact of adherence to current dietary guidelines whereas the NOVA classification allows measurement of the caloric contribution of UPP to total daily dietary energy intake - a proxy for intakes of food products with low nutritional quality.

Logistic regression was used to describe the relationship between quintiles of diet quality scores and MetS. Models were adjusted for age, sex, area of residence, total daily dietary energy intake, alcohol and smoking status.

Statistical analyses were conducted with a two-sided significance level of $\alpha=5 \%$ using the statistical software package SAS version 9.4 . 


\section{Results}

The mean age of our study population was $36 \cdot 4$ (95\% CI $35 \cdot 4,37 \cdot 4$ ) years and $59 \%$ were female ( $n$ 476; Table 3). A large majority of the Eeyouch adults in our study were obese (70\%), with an additional $21 \%$ who were overweight, and on average BMI was 33.1 (95\% CI $32.7,33 \cdot 6) \mathrm{kg} / \mathrm{m}^{2}$. Central obesity was found in $95 \%$ of participants.

In our sample, the most common metabolic disturbance was elevated FPG above $5.6 \mathrm{mmol} / \mathrm{l}(50 \%)$ followed by reduced HDL-C level (45\%). Forty-three per cent presented hypertension and 39\% had elevated TAG. MetS was identified in more than half of our sample (56.6\%). Participants with MetS were older and had higher BMI.

Diet quality assessment from the aHEI-2010 scores ranged from $13 \cdot 2$ to 68.9 with a mean of $36 \cdot 3$ (sD 10.7) out of a maximum score of 110 (Table 4). From a maximum possible score of 70, mean FQS was 38.2 (SD 6.4) and ranged from 20 to 58 . The contribution of UPP to total daily dietary energy intake consumed by Eeyouch varied from 0 to $100 \%$ with a mean of 51.9 (sD 22.9) \%. Pearson correlation coefficients between all three diet quality scores were the strongest between aHEI-2010 and FQS $(r=0.52)$. When comparing with the dietary share of UPP, negative correlations were observed with the aHEI-2010 score $(r=-0 \cdot 47)$ as well as with the FQS $(r=-0 \cdot 29)$. All correlations were significant $(P<0 \cdot 0001$; data not shown).
Dietary intake by aHEI-2010 score quintiles is provided in the Appendix.

After adjustment for potential confounding variables, diet quality scores showed a significant trend with prevalence of MetS in one model (Table 4). Higher quintiles of energy contribution of UPP showed significant association with MetS $(\mathrm{OR}=1.90 ; 95 \%$ CI 1.14, 3.17; $P$-trend =0.04). A marginally significant lower trend $(P=0.05)$ of MetS was observed for aHEI-2010 quintiles, but only the fourth quintile was statically significant $(\mathrm{OR}=0.56$; $95 \%$ CI 0.35, 0.89).

Addressing the MetS diagnosis criteria independently (Table 5), we observed a higher prevalence of reduced HDL-C with an increased contribution of UPP ( $P$-trend $=$ 0.02). A significant trend towards lower risk of elevated WC was observed with higher FQS $(P$-trend $=0 \cdot 04)$. The OR of elevated WC was $0 \cdot 25$ (95\% CI $0 \cdot 07,0 \cdot 82)$ for the highest quintile, compared with the lowest.

\section{Discussion}

The present study reports the first available information on diet quality and food processing relating to MetS among Indigenous peoples, notably Eeyouch adults from Eastern James Bay (Québec). Diet quality scores (aHEI-2010, FQS) were very low and the contribution of UPP to energy intake was relatively high at $52 \%$. When assessing the

Table 3 Characteristics of Eeyou adults ( $\geq 18$ years old) from seven northern Québec communities, Canada, 2005-2009 Nituuchischaayihititaau Aschii Environment-and-Health Study

\begin{tabular}{|c|c|c|c|c|c|c|}
\hline & \multicolumn{4}{|c|}{ Metabolic syndrome* } & & \\
\hline & \multicolumn{2}{|c|}{ No $(n$ 352) } & \multicolumn{2}{|c|}{ Yes $(n$ 459) } & \multicolumn{2}{|c|}{ All $(n 811)$} \\
\hline & $\begin{array}{l}\text { Geometric } \\
\text { mean or \% }\end{array}$ & $95 \% \mathrm{Cl}$ & $\begin{array}{l}\text { Geometric } \\
\text { mean or \% }\end{array}$ & $95 \% \mathrm{Cl}$ & $\begin{array}{l}\text { Geometric } \\
\text { mean or \% }\end{array}$ & $95 \% \mathrm{Cl}$ \\
\hline Sex (\% women) & $58 \cdot 8$ & - & 58.6 & - & $58 \cdot 7$ & - \\
\hline Age (years) & $31 \cdot 3$ & $30 \cdot 1,32 \cdot 5$ & $40 \cdot 8$ & $39.5,42 \cdot 3$ & $36 \cdot 4$ & $35 \cdot 4,37 \cdot 4$ \\
\hline Area of residence (\% coastal) & 73.9 & - & $65 \cdot 1$ & - & 68.9 & - \\
\hline Current smokers (\%) & 63.9 & - & $42 \cdot 3$ & - & $51 \cdot 7$ & - \\
\hline Alcohol drinkers (\%) & $30 \cdot 4$ & - & 21.4 & - & $25 \cdot 3$ & _- \\
\hline BMI $\left(\mathrm{kg} / \mathrm{m}^{2}\right)$ & $30 \cdot 4$ & $29 \cdot 8,31 \cdot 1$ & 35.4 & $34 \cdot 8,36 \cdot 0$ & $33 \cdot 1$ & $32 \cdot 7,33 \cdot 6$ \\
\hline Normal weight (\%) & 18.5 & - & 0.9 & - & 8.5 & - \\
\hline Overweight (\%) & $26 \cdot 7$ & - & $17 \cdot 2$ & - & 21.3 & - \\
\hline Obese (\%) & 54.8 & - & 81.9 & - & $70 \cdot 2$ & - \\
\hline $\mathrm{WC}(\mathrm{cm})$ & 104 & 102,105 & 116 & 115,117 & 110 & 109,112 \\
\hline Men $\geq 90 \mathrm{~cm}$, women $\geq 80 \mathrm{~cm}(\%)$ & 89.8 & - & 99.8 & - & 95.4 & - \\
\hline $\mathrm{FPG}(\mathrm{mmol} / \mathrm{l})$ & $5 \cdot 20$ & $5 \cdot 13,5 \cdot 28$ & 6.67 & $6 \cdot 49,6 \cdot 87$ & 5.99 & $5 \cdot 88,6 \cdot 11$ \\
\hline Normal (<5.6 mmol/l; \%) & 84.9 & - & $23 \cdot 1$ & - & 49.9 & - \\
\hline IFG (5.6-6.9 mmol//; \%) & $12 \cdot 8$ & - & $50 \cdot 3$ & - & $34 \cdot 0$ & - \\
\hline Diabetes ( $\geq 7.0 \mathrm{mmol} / \mathrm{l} ; \%)$ & $2 \cdot 3$ & - & $26 \cdot 6$ & - & $16 \cdot 0$ & - \\
\hline $\mathrm{SBP}(\mathrm{mmHg})$ & 115 & 113,116 & 125 & 124,127 & $120 \cdot 5$ & 120,122 \\
\hline$\geq 130 \mathrm{mmHg}(\%)$ & 8.8 & - & 39.7 & - & $26 \cdot 3$ & - \\
\hline $\mathrm{DBP}(\mathrm{mmHg})$ & $70 \cdot 3$ & $69 \cdot 2,71.4$ & 75.4 & $74 \cdot 3,76 \cdot 4$ & $73 \cdot 1$ & $72 \cdot 3,73.9$ \\
\hline$\geq 85 \mathrm{mmHg}(\%)$ & 5.7 & - & $21 \cdot 6$ & - & $14 \cdot 7$ & - \\
\hline Hypertension $(\geq 130 / 85 \mathrm{mmHg})$ & 13.9 & - & $66 \cdot 0$ & - & 43.4 & - \\
\hline $\mathrm{TAG}(\mathrm{mmol} / \mathrm{l})$ & 1.08 & $1.04,1.12$ & 1.68 & $1.61,1.75$ & 1.39 & $1.34,1.43$ \\
\hline$\geq 1.7 \mathrm{mmol} / \mathrm{l}(\%)$ & $7 \cdot 1$ & - & $62 \cdot 8$ & - & 38.6 & - \\
\hline $\mathrm{HDL}-\mathrm{C}(\mathrm{mmol} / \mathrm{l})$ & 1.34 & $1.31,1.37$ & $1 \cdot 12$ & $1.09,1.14$ & 1.21 & $1.19,1.23$ \\
\hline Men $\leq 1.03 \mathrm{mmol} / \mathrm{l}$, women $\leq 1.29 \mathrm{mmol} / \mathrm{l}(\%)$ & $25 \cdot 3$ & - & $59 \cdot 3$ & - & 44.5 & - \\
\hline
\end{tabular}

WC, waist circumference; FPG, fasting plasma glucose; IFG, impaired fasting glucose; SBP, systolic blood pressure; DBP, diastolic blood pressure; HDL-C, HDL cholesterol.

*Based on the MetS harmonized definition (see criteria in Table 2). 
Table 4 Adjusted odds of metabolic syndrome (MetS) ${ }^{\star}$ according to diet quality score quintiles of Eeyou adults ( $\geq 18$ years old) from seven northern Québec communities, Canada, 2005-2009 Nituuchischaayihititaau Aschii Environment-and-Health Study

\begin{tabular}{|c|c|c|c|c|c|c|c|c|c|c|c|c|c|}
\hline & \multicolumn{10}{|c|}{ Diet quality score quintiles } & \multirow[b]{3}{*}{$P$-trend } & & \\
\hline & \multicolumn{2}{|r|}{ Q1 } & \multicolumn{2}{|r|}{ Q2 } & \multicolumn{2}{|r|}{ Q3 } & \multicolumn{2}{|r|}{ Q4 } & \multicolumn{2}{|r|}{ Q5 } & & \multicolumn{2}{|c|}{ Per increment† } \\
\hline & OR & $95 \% \mathrm{Cl}$ & OR & $95 \% \mathrm{Cl}$ & OR & $95 \% \mathrm{Cl}$ & OR & $95 \% \mathrm{Cl}$ & OR & $95 \% \mathrm{Cl}$ & & OR & $95 \% \mathrm{Cl}$ \\
\hline \multicolumn{14}{|l|}{ aHEl-2010 } \\
\hline Median score & \multirow{2}{*}{\multicolumn{2}{|c|}{$\begin{array}{c}22 \cdot 8 \\
13 \cdot 2-26 \cdot 9\end{array}$}} & \multicolumn{2}{|c|}{$29 \cdot 8$} & \multicolumn{2}{|r|}{$35 \cdot 1$} & \multicolumn{2}{|c|}{$42 \cdot 3$} & \multicolumn{2}{|r|}{50.7} & & & \\
\hline Min.-max. score & & & \multicolumn{2}{|c|}{$26 \cdot 9-32 \cdot 6$} & \multicolumn{2}{|c|}{$32 \cdot 6-38 \cdot 3$} & \multicolumn{2}{|c|}{$38.4-45.8$} & \multicolumn{2}{|c|}{$45 \cdot 8-68 \cdot 9$} & & & \\
\hline No. of cases & \multicolumn{2}{|c|}{89} & \multicolumn{2}{|c|}{95} & \multicolumn{2}{|c|}{73} & \multicolumn{2}{|c|}{97} & \multicolumn{2}{|c|}{105} & & & \\
\hline No. of non-cases & \multicolumn{2}{|c|}{73} & & 67 & & 90 & \multicolumn{2}{|r|}{65} & \multicolumn{2}{|r|}{57} & & & \\
\hline Age-adjusted & 1.00 & Ref. & 0.88 & $0.55,1.40$ & 0.78 & $0.48,1.24$ & 0.54 & $0.34,0.85$ & 0.65 & $0.39,1.08$ & 0.67 & 0.75 & $0.49,1.13$ \\
\hline Multivariate model§ & 1.00 & Ref. & 0.89 & $0.56,1.42$ & 0.83 & $0.51,1.35$ & 0.56 & $0.35,0.89$ & 0.70 & $0.42,1 \cdot 18$ & 0.05 & 0.81 & $0.53,1.24$ \\
\hline \multicolumn{14}{|l|}{ FQS $\ddagger$} \\
\hline Median score & \multicolumn{2}{|c|}{$30 \cdot 0$} & \multicolumn{2}{|c|}{$35 \cdot 0$} & \multicolumn{2}{|c|}{38.0} & & 41.0 & & $47 \cdot 0$ & & & \\
\hline Min.-max. score & $20 \cdot($ & $0-32 \cdot 0$ & & $3 \cdot 0-36 \cdot 0$ & & $7 \cdot 0-39 \cdot 0$ & & $0.0-43.0$ & & $4.0-58.0$ & & & \\
\hline No. of cases & & 78 & & 86 & & 78 & & 104 & & 113 & & & \\
\hline No. of non-cases & & 89 & & 73 & & 78 & & 53 & & 59 & & & \\
\hline Age-adjusted & 1.00 & Ref. & $1 \cdot 19$ & $0.75,1.87$ & 0.76 & $0.47,1.21$ & $1 \cdot 27$ & $0.78,2.06$ & 1.05 & $0.65,1.70$ & 0.78 & 0.93 & $0.61,1.42$ \\
\hline Multivariate model§ & 1.00 & Ref. & 1.25 & $0.78,1.99$ & 0.79 & $0.49,1.28$ & 1.24 & $0.75,2.06$ & 1.06 & $0.63,1.76$ & 0.87 & 0.91 & $0.58,1.43$ \\
\hline NOVA $\|$ & & & & & & & & & & & & & \\
\hline Median score & & $21 \cdot 1$ & & 38.0 & & $52 \cdot 0$ & & 64.9 & & 83.0 & & & \\
\hline Min.-max. score & 0.00 & $0-30 \cdot 2$ & & $0.2-45.5$ & & $5 \cdot 7-58 \cdot 3$ & & $8 \cdot 3-72 \cdot 5$ & & $2 \cdot 6-100$ & & & \\
\hline No. of cases & & 96 & & 96 & & 99 & & 81 & & 87 & & & \\
\hline No. of non-cases & & 66 & & 66 & & 64 & & 81 & & 75 & & & \\
\hline Age-adjusted & 1.00 & Ref. & 1.45 & $0.90,2.36$ & 1.90 & $1 \cdot 16,3 \cdot 10$ & 1.39 & $0.85,2.27$ & 1.96 & $1 \cdot 18,3 \cdot 25$ & 0.03 & 1.69 & $1.09,2.64$ \\
\hline Multivariate model§ & 1.00 & Ref. & 1.49 & $0.91,2.43$ & 1.90 & $1 \cdot 15,3 \cdot 13$ & 1.38 & $0.84,2.28$ & 1.90 & $1.14,3.17$ & 0.04 & 1.65 & $1.05,2.59$ \\
\hline
\end{tabular}

aHEI-2010, alternative Healthy Eating Index 2010; min.-max., minimum-maximum; FQS, Food Quality Score; ref., reference category.

*Based on the MetS harmonized definition (see criteria in Table 2).

†The per-increment scale represents the difference between 90 th and 10th percentiles of each diet quality index and was 27.9 for aHEI-2010, 17 for FQS and 0.62 for NOVA.

¥Q1 represents lower scores (worst) whereas Q5 the highest scores (better).

$\S$ Adjusted for age (continuous), sex, area of residence (coastal/inland), current smoker (yes/no), alcohol drinker (yes/no, except for the aHEl-2010 model) and total dietary energy intake (kcal/d, continuous).

॥Q1 represents the lowest contribution of ultra-processed foods (best) whereas Q5 the highest contribution (worst).

aHEI-2010, FQS and contribution of UPP to total daily dietary energy intake with risk of MetS, the contribution of UPP showed the strongest association. However, no significant association was observed with the diet quality scores provided by aHEI-2010 and FQS.

Eeyouch participants in our study suffered from a heavy burden of MetS (57\%), approximately 2.7 times higher than that among the general Canadian population ${ }^{(36)}$, despite a younger average age among the Eeyouch. These rates are consistent with those found in Cree communities from western Canada $^{(15)}$. Other First Nations populations in Canada have reported (2006) lower rates of MetS (range 16.0$37.5 \%)^{(37)}$. Chateau-Degat et al. ${ }^{(14)}$ observed lower rates (men $21.1 \%$, women $25 \cdot 1 \%$ ) of MetS (2005 International Diabetes Federation definition) among James Bay Cree in 1990-1992 than those found in our study (men $56.7 \%$, women $56.5 \%$ ). Wide variation in prevalence of MetS risk factors has been observed among different ethnic groups, such as the WC cutoffs $^{(15,33)}$. As such, elevated TAG and impaired fasting glucose are considered good indicators of MetS in most populations ${ }^{(33)}$. The high prevalence of MetS in our study (57\%) was accompanied by a very high rate of obesity (70\%) and central adiposity (95\%). This is also consistent with observations from Canadian, American and European studies ${ }^{(38)}$.

The current study on the association between diet quality indices and the prevalence of MetS among
Eeyouch may contribute to our knowledge of the current nutritional environment and transition that many Indigenous populations are facing ${ }^{(39)}$.

In recent years, several diet quality scores have been developed as an alternative to studying the intake of single nutrients to better reflect diet complexity ${ }^{(1,40)}$. Many epidemiological studies have observed strong associations between diet quality scores and cardiometabolic risks. Moubarac et al. ${ }^{(23)}$ observed that UPP in Canada have a higher energy density and contain more free sugar, fat and salt than non ultra-processed products (fresh or minimally processed food, culinary ingredients and processed food together). The limited intake of fresh and unprocessed foods and the importance of energy-dense products in Canadian Aboriginal communities' diets are corroborated by several studies ${ }^{(22,26,41-43)}$.

Our findings agreed with other epidemiological research focusing on the relationship between UPP and health ${ }^{(25,44-51)}$. For the prevention and management of obesity, T2DM and other chronic diseases, the Canadian evidence has shown that UPP should contribute less than one-third to total daily dietary energy intake in order to meet the WHO recommendations for fat, free sugars, sodium and fibre intake ${ }^{(23)}$. The contribution (52\%) of UPP to total daily dietary energy intake in our sample is well above that recommendation. It is also higher than the 
Table 5 Multivariate adjusted* odds of components of the metabolic syndrome (MetS) $\dagger$ according to diet quality score quintiles of Eeyou adults ( $\geq 18$ years old) from seven northern Québec communities, Canada, 2005-2009 Nituuchischaayihititaau Aschii Environment-andHealth Study

\begin{tabular}{|c|c|c|c|c|c|c|c|c|c|c|c|c|c|}
\hline & \multicolumn{10}{|c|}{ Diet quality score quintiles } & \multirow[b]{3}{*}{$P$-trend } & \multirow{2}{*}{\multicolumn{2}{|c|}{ Per incrementł }} \\
\hline & \multicolumn{2}{|r|}{ Q1 } & \multicolumn{2}{|r|}{ Q2 } & \multicolumn{2}{|r|}{ Q3 } & \multicolumn{2}{|r|}{ Q4 } & \multicolumn{2}{|r|}{ Q5 } & & & \\
\hline & OR & $95 \% \mathrm{Cl}$ & OR & $95 \% \mathrm{Cl}$ & OR & $95 \% \mathrm{Cl}$ & OR & $95 \% \mathrm{Cl}$ & OR & $95 \% \mathrm{Cl}$ & & OR & $95 \% \mathrm{Cl}$ \\
\hline \multicolumn{14}{|l|}{ aHEI-2010§ } \\
\hline WC & 1.00 & Ref. & 1.64 & $0.55,4.94$ & 0.87 & $0.35,2 \cdot 13$ & 1.02 & $0.35,2.95$ & 1.08 & $0.30,3.95$ & 0.62 & 0.93 & $0.30,2.87$ \\
\hline TAG & 1.00 & Ref. & 1.28 & $0.80,2.02$ & 0.73 & $0.45,1.17$ & 0.98 & $0.60,1.56$ & 0.92 & $0.56,1.51$ & 0.37 & 0.86 & $0.57,1.31$ \\
\hline HDL-C & 1.00 & Ref. & 0.89 & $0.56,1.42$ & 0.64 & $0.40,1.03$ & 0.97 & $0.60,1.56$ & 0.95 & $0.57,1.56$ & 0.88 & 0.88 & $0.58,1.34$ \\
\hline Hypertension & 1.00 & Ref. & 1.20 & $0.74,1.97$ & 0.88 & $0.53,1.45$ & $0 \cdot 83$ & $0.49,1.39$ & $1 \cdot 11$ & $0.65,1.90$ & 0.74 & 1.01 & $0.65,1.57$ \\
\hline $\begin{array}{l}\text { FPG } \\
\text { FQS§ }\end{array}$ & 1.00 & Ref. & $1 \cdot 16$ & $0.72,1.88$ & 0.91 & $0.56,1.48$ & 1.04 & $0.63,1.71$ & 1.01 & $0.60,1.71$ & 0.85 & 1.04 & $0.67,1.61$ \\
\hline WC & 1.00 & Ref. & 0.77 & $0.27,2.19$ & 0.79 & $0.25,2.57$ & 0.59 & $0 \cdot 17,2 \cdot 10$ & 0.25 & $0.07,0.82$ & 0.04 & 0.32 & $0.11,0.94$ \\
\hline TAG & 1.00 & Ref. & 1.42 & $0.88,2.27$ & $1 \cdot 11$ & $0.68,1.81$ & 1.38 & $0 \cdot 84,2 \cdot 27$ & $1 \cdot 14$ & $0.68,1.90$ & 0.72 & 1.02 & $0.66,1.58$ \\
\hline HDL-C & 1.00 & Ref. & 0.89 & $0.56,1.41$ & 0.77 & $0.47,1.24$ & 0.86 & $0.53,1.41$ & 1.00 & $0.60,1.64$ & 0.98 & 0.91 & $0.59,1.41$ \\
\hline Hypertension & 1.00 & Ref. & 0.92 & $0.56,1.52$ & 0.93 & $0.56,1.56$ & 0.91 & $0.53,1.54$ & 0.83 & $0.48,1.42$ & 0.52 & 0.82 & $0.51,1.32$ \\
\hline $\begin{array}{l}\text { FPG } \\
\text { NOVA }\end{array}$ & 1.00 & Ref. & $1 \cdot 11$ & $0.69,1.81$ & 0.93 & $0.56,1.53$ & 1.58 & $0.94,2.67$ & 0.77 & $0.45,1.30$ & 0.73 & 0.85 & $0.54,1.35$ \\
\hline WC & 1.00 & Ref. & 1.07 & $0.26,4.39$ & 1.26 & $0.32,4.95$ & 0.84 & $0.24,2.88$ & $1 \cdot 18$ & $0.33,4.32$ & 0.98 & $1 \cdot 10$ & $0.38,3.17$ \\
\hline TAG & 1.00 & Ref. & 0.96 & $0.61,1.52$ & 1.02 & $0.64,1.63$ & 0.89 & $0.55,1.44$ & 0.93 & $0.57,1.52$ & 0.71 & 1.01 & $0.66,1.55$ \\
\hline HDL-C & 1.00 & Ref. & 1.25 & $0.78,2.00$ & 1.44 & $0.89,2.32$ & 1.72 & $0.72,1.92$ & $2 \cdot 05$ & $1 \cdot 25,3.38$ & 0.02 & 1.87 & $1.21,2.90$ \\
\hline Hypertension & 1.00 & Ref. & 0.92 & $0.56,1.51$ & $1 \cdot 31$ & $0 \cdot 79,2 \cdot 16$ & 1.01 & $0.60,1.69$ & 0.99 & $0.59,1.68$ & 0.91 & 1.03 & $0.65,1.63$ \\
\hline FPG & 1.00 & Ref. & 1.65 & $1.00,2.74$ & 1.95 & $1 \cdot 17,3.25$ & 1.40 & $0.84,2.35$ & 1.76 & $1.04,2.97$ & 0.14 & 1.45 & $0.92,2.30$ \\
\hline
\end{tabular}

aHEI-2010, alternative Healthy Eating Index 2010; WC, waist circumference; HDL-C, HDL cholesterol; FPG; fasting plasma glucose; FQS, Food Quality Score; ref., reference category.

*Adjusted for age (continuous), sex, area of residence (coastal/inland), current smoker (yes/no), alcohol drinker (yes/no, except for the aHEI-2010 model) and total dietary energy intake ( $\mathrm{kcal} / \mathrm{d}$, continuous).

†Based on the MetS harmonized threshold (see criteria in Table 2).

¥The per-increment scale represents the difference between 90th and 10th percentiles of each diet quality index and was 27.9 for aHEI-2010, 17 for FQS and 0.62 for NOVA.

$\S \mathrm{Q} 1$ represents lower scores (worst) whereas Q5 the highest scores (better).

$\|$ Q1 represents the lowest contribution of ultra-processed foods (best) whereas Q5 the highest contribution (worst).

Québec average of $47 \%{ }^{(52)}$. UPP have been associated with $\operatorname{MetS}^{(49)}$, obesity ${ }^{(11,46,47,53)}$, lipid profile ${ }^{(44)}$ and $\mathrm{CVD}^{(51)}$.

Lower aHEI-2010 scores have been strongly associated with chronic disease risk, particularly $\mathrm{T}_{2} \mathrm{DM}^{(2)}$ and obesity $^{(54)}$. Mean aHEI-2010 score in our sample was $36 \cdot 3$ (range 13.2-68.9), which is similar to the average found by Boggs et $a l{ }^{(54)}$. These scores are considerably lower than in other study populations, even in regions with lower socio-economic status ${ }^{(2,55,56)}$. This agrees with current knowledge of the dietary environment of Canadian First Nation communities ${ }^{(21,57-59)}$. Although the aHEI-2010 score is built on strong epidemiological evidence ${ }^{(2,54,55)}$, the index has never been validated in an Aboriginal setting. The low scores may relate to inadequacy of the tool with the specificities of Eeyouch Istchee communities. The distribution of aHEI-2010 scores in our sample is within the lower half of the scale out of a possible maximum score of 110 . The very low scores of aHEI-2010 might explain why comparing highest (45.8-68.9) and lowest (13.2-26.9) score quintiles showed no significant association. The highest score quintile in our sample may not translate into statistically significant health benefits.

Although the FQS did not show a significant association with MetS in our sample, the FQS stands out by its simplicity and the absence of reliance on nutrient intake ${ }^{(3)}$. This represents a net advantage in clinical and research contexts where traditional dietary evaluations take a considerable time to complete and analyse. Unfortunately, the current tool may not be appropriate in the First Nations context. Items such as whole grains and nuts represent only small portions of the Cree diet ${ }^{(22)}$. Therefore, a dietary assessment tool with a food-based checklist tailored to the Indigenous situation would be of great help in clinical and research settings. This list could identify foods that have been associated with chronic disease in Indigenous peoples. Beside specific products, these indices do not discriminate food products based on the processing level. This represents another limit of these indices.

\section{Strengths of the study}

To our knowledge, the present study is the first to assess the pertinence in a Canadian Indigenous context of three dietary quality indices (aHEI-2010, FQS and the contribution of UPP to total daily dietary energy intake using the NOVA classification). It is also the first to study the relationship between these indices and MetS. Considering the random recruitment method, the prevalence of MetS reported is most likely representative of the real prevalence in adult Eeyouch from Eastern James Bay, Québec. Our data confirming high rates of MetS in Eeyouch with respect to the important contribution of UPP to the diet are therefore particularly striking. 


\section{Weaknesses of the study}

Information bias is inherent to all dietary recall methods ${ }^{(60,61)}$. It has been shown that certain foods which are present in FQS and aHEI-2010 lists are forgotten or omitted in $24 \mathrm{~h} \mathrm{recall}^{(62)}$. However, the five-step multiplepass method, including a list of often forgotten foods, ensures a greater reliability of dietary food intake ${ }^{(29,62,63)}$. Finally, the $24 \mathrm{~h}$ recall was not designed to use the NOVA classification; therefore, some foods could have been misclassified due to lack of sufficient details.

The cross-sectional design of the study is another limitation and does not allow us to determine any causal relationships. Moreover, it is possible that participants with high MetS risk factors may have already made changes to their diet that could not be identified in the current study design. Therefore, prospective studies are needed.

\section{Conclusion}

Our results suggest a high prevalence of MetS among Eeyouch adults from Eastern James Bay, Québec. The NOVA classification, particularly the contribution of UPP to total daily dietary energy intake, provides the strongest relationship with MetS. These results support the use of UPP contribution to total daily dietary energy intake as a new meaningful predictive indicator of overall diet nutritional quality. Although the overall scores calculated by the three indices used in the present study suggest a low diet quality in these communities, more pertinent and culturally adapted instruments are needed to fully understand the impact of diet quality on MetS. These results support the importance of developing tools that are tailored to the particular nutritional environment in Canadian Indigenous communities. Further research should also address determinants of diet quality, especially food availability, access and utilization (knowledge and preferences).

\section{Acknowledgements}

Acknowledgements: The authors would like to thank the Eeyou communities that participated and all the staff from the communities, the Cree Board of Health and Social Service of James Bay and universities who made this project a success. Financial support: This scientific communication is a report from the Nituuchischaayibtitaau Aschii: Multi-Community Environment-and-Health Longitudinal Study in Iiyiyiu Aschii supported by the Cree people of northern Québec, the Cree First Nations and the Cree Board of Health and Social Services of James Bay through financial contributions from Niskamoon Corporation (agreement number 2005.06). M.L.-R. was supported by the Recruitment Master's Scholarship 2015-2016 Wilbrod-Bherer from Laval University, the 2016 Canada Graduate Scholarships-Master's and the 2016-2017 CHU Foundation of Quebec. The funders had no role in the design, analysis or writing of this article. Conflict of interest: None. Authorship: L.J.-D. participated in the data collection; M.L.-R., E.A.L.S., J.-C.M. and M.L. designed the analysis; S.L.-L., J.-C.M., M.L.-R. and E.A.L.S. contributed to the data analysis; M.L.-R. conducted the analysis and interpretation and wrote the first draft of the manuscript; J.-C.M., S.L.-L., L.J.-D., M.B. and M.L. critically revised the manuscript for important intellectual content; M.L. had primary responsibility for the manuscript final content. All authors read and approved the final version of the manuscript. Etbics of buman subject participation: This study was conducted according to the guidelines laid down in the Declaration of Helsinki and all procedures involving human subjects/patients were approved by the Laval University, McMaster University, McGill University and the Cree Board of Health and Social Services of James Bay ethics committees. Written informed consent was obtained from all participants.

\section{References}

1. Hu FB (2002) Dietary pattern analysis: a new direction in nutritional epidemiology. Curr Opin Lipidol 13, 3-9.

2. Chiuve SE, Fung TT, Rimm EB et al. (2012) Alternative dietary indices both strongly predict risk of chronic disease. J Nutr 142, 1009-1018.

3. Fung TT, Pan A, Hou T et al. (2016) Food quality score and the risk of coronary artery disease: a prospective analysis in 3 cohorts. Am J Clin Nutr 104, 65-72.

4. Vandevijvere S, Monteiro C, Krebs-Smith SM et al. (2013) Monitoring and benchmarking population diet quality globally: a step-wise approach. Obes Rev 14, Suppl. 1, 135-149.

5. Martínez-González MA, Salas-Salvadó J, Estruch $\mathrm{R}$ et al. (2015) Benefits of the Mediterranean diet: insights from the PREDIMED study. Prog Cardiovasc Dis 58, 50-60.

6. Ros E, Martinez-Gonzalez MA, Estruch R et al. (2014) Mediterranean diet and cardiovascular health: teachings of the PREDIMED study. Adv Nutr 5, issue 3, 330S-336S.

7. Sofi F, Abbate R, Gensini GF et al. (2010) Accruing evidence on benefits of adherence to the Mediterranean diet on health: an updated systematic review and meta-analysis. $\mathrm{Am}$ J Clin Nutr 92, 1189-1196.

8. Schulze M, Nothlings U, Hoffmann K et al. (2005) Identification of a food pattern characterized by high-fiber and low-fat food choices associated with low prospective weight change in the EPIC-Potsdam cohort. $J$ Nutr $\mathbf{1 3 5}$, 1183-1189.

9. Newby PK, Muller D, Hallfrisch J et al. (2004) Food patterns measured by factor analysis and anthropometric changes in adults. Am J Clin Nutr 80, 504-513.

10. Schulze MB, Fung TT, Manson JE et al. (2006) Dietary patterns and changes in body weight in women. Obesity (Silver Spring) 14, 1444-1453.

11. Mendonça R de D, Pimenta AM, Gea A et al. (2016) Ultraprocessed food consumption and risk of overweight and obesity: the University of Navarra Follow-Up (SUN) cohort study. Am J Clin Nutr 105, 1433-1440.

12. Reading J (2007) The Crisis of Chronic Disease among Aboriginal Peoples: A Challenge for Public Health, Population Health and Social Policy. Victoria, BC: Centre for Aboriginal Health Research.

13. National Collaborating Centre for Aboriginal Health (2013) An Overview of Aboriginal Health in Canada. Prince George, BC: NCCAH. 
14. Chateau-Degat M-L, Dewailly E, Poirier P et al. (2008) Comparison of diagnostic criteria of the metabolic syndrome in 3 ethnic groups of Canada. Metabolism 57, 1526-1532.

15. Kaler SN, Ralph-Campbell K, Pohar S et al. (2006) High rates of the metabolic syndrome in a First Nations community in western Canada: prevalence and determinants in adults and children. Int J Circumpolar Health 65, 389-402.

16. Young TK, Reading J, Elias B et al. (2000) Type 2 diabetes mellitus in Canada's First Nations: status of an epidemic in progress. CMAJ 163, 561-566.

17. Pelletier C, Dai S, Roberts KC et al. (2012) Report summary. Diabetes in Canada: facts and figures from a public health perspective. Chronic Dis Inj Can 33, 53-54.

18. Green C, Blanchard JF, Young TK et al. (2003) The epidemiology of diabetes in the Manitoba-registered first nation population: current patterns and comparative trends. Diabetes Care 26, 1993-1998.

19. Nieboer E, Dewailly E, Johnson-Down L et al. (2013) Nituuchischaayihtitaau Aschii Multi-Community Environmentand-Health Study in Eeyou Istchee 2005-2009. http://www. creehealth.org/sites/default/files/E-and-H-\%20Summary\% 20report_Final\%2002-10-15.pdf (accessed March 2016).

20. Ngueta $\bar{G}$, Laouan-Sidi AE \& Lucas M (2014) Does waist circumference uncorrelated with BMI add valuable information? J Epidemiol Community Health 68, 849-855.

21. Johnson-Down LM \& Egeland GM (2013) How is nutrition transition affecting dietary adequacy in Eeyouch (Cree) adults of Northern Quebec, Canada? Appl Physiol Nutr Metab 38, 300-305.

22. Johnson-Down L, Labonte ME, Martin ID et al. (2015) Quality of diet is associated with insulin resistance in the Cree (Eeyouch) indigenous population of northern Québec. Nutr Metab Cardiovasc Dis 25, 85-92.

23. Moubarac J, Martins APB, Claro RM et al. (2013) Consumption of ultra-processed foods and likely impact on human health. Evidence from Canada. Public Health Nutr 16, 2240-2248.

24. Louzada ML, Martins APB, Canella DS et al. (2015) Ultraprocessed foods and the nutritional dietary profile in Brazil. Rev Saude Publica 49, 38 .

25. Steele EM, Baraldi LG, Louzada ML da C et al. (2016) Ultraprocessed foods and added sugars in the US diet: evidence from a nationally representative cross-sectional study. BMJ Open 6, e009892.

26. Downs SM, Arnold A, Marshall D et al. (2009) Associations among the food environment, diet quality and weight status in Cree children in Québec. Public Health Nutr 12, 1504-1511.

27. Khalil CB, Johnson-Down L \& Egeland GM (2010) Emerging obesity and dietary habits among James Bay Cree youth. Public Health Nutr 13, 1829-1837.

28. Schwingshackl L \& Hoffmann G (2015) Diet quality as assessed by the Healthy Eating Index, the Alternate Healthy Eating Index, the Dietary Approaches to Stop Hypertension Score, and health outcomes: a systematic review and metaanalysis of cohort studies. J Acad Nutr Diet 115, 780-800.e5.

29. Conway JM, Ingwersen LA \& Moshfegh AJ (2004) Accuracy of dietary recall using the USDA five-step multiple-pass method in men: an observational validation study. J Am Diet Assoc 104, 595-603.

30. Alberti KGMM, Eckel RH, Grundy SM et al. (2009) Harmonizing the metabolic syndrome: a joint interim statement of the International Diabetes Federation Task Force on Epidemiology and Prevention; National Heart, Lung, and Blood Institute; American Heart Association; World Heart Federation; International Atherosclerosis Society; and International Association for the Study of Obesity. Circulation 120, 1640-1645.

31. World Health Organization (2000) Obesity: Preventing and Managing the Global Epidemic. Report of a WHO Consultation. WHO Technical Report Series no. 894. Geneva: World Health Organization.
32. Anand SS (2004) C-reactive protein as a screening test for cardiovascular risk in a multiethnic population. Arterioscler Thromb Vasc Biol 24, 1509-1515.

33. Delisle H, Desilets MC, Vargas ER et al. (2008) Metabolic syndrome in three ethnic groups using current definitions. Appl Physiol Nutr Metab 33, 356-360.

34. Alberti KGMM, Zimmet P \& Shaw J (2006) Metabolic syndrome - a new world-wide definition. A consensus statement from the International Diabetes Federation. Diabet Med 23, 469-480.

35. Touyz RM (2006) Highlights and summary of the 2006 Canadian Hypertension Education Program recommendations. Can J Cardiol 22, 565-571.

36. Statistics Canada (2014) Metabolic syndrome in adults, 2012 to 2013. Catalogue no. 82-625-X2014001. http://www. statcan.gc.ca/pub/82-625-x/2014001/article/14123-eng.htm (accessed October 2016).

37. Liu J, Hanley AJG, Young TK et al. (2006) Characteristics and prevalence of the metabolic syndrome among three ethnic groups in Canada. Int J Obes (Lond) 30, 669-676.

38. Grundy SM (2008) Metabolic syndrome pandemic. Arterioscler Thromb Vasc Biol 28, 629-636.

39. Popkin BM (2004) The nutrition transition: an overview of world patterns of change. Nutr Rev 62, Suppl. 2, S140-S143.

40. Patterson RE, Haines PS \& Popkin BM (1994) Diet quality index: capturing a multidimensional behavior. J Am Diet Assoc 94, 57-64.

41. Downs SM, Marshall D, Ng C et al. (2008) Central adiposity and associated lifestyle factors in Cree children. Appl Physiol Nutr Metab 33, 476-482.

42. Willows ND (2005) Determinants of healthy eating in Aboriginal peoples in Canada: the current state of knowledge and research gaps. Can J Public Health 96, Suppl. 3, S32-S36.

43. Kuhnlein HV, Receveur O, Soueida R et al. (2004) Arctic indigenous peoples experience the nutrition transition with changing dietary patterns and obesity. J Nutr 134, 1447-1453.

44. Rauber F, Campagnolo PDB, Hoffman DJ et al. (2015) Consumption of ultra-processed food products and its effects on children's lipid profiles: a longitudinal study. Nutr Metab Cardiovasc Dis 25, 116-122.

45. Moubarac J-C, Batal M, Martins APB et al. (2014) Processed and ultra-processed food products: consumption trends in Canada from 1938 to 2011. Can J Diet Pract Res 75, 15-21.

46. Canella DS, Levy RB, Martins APB et al. (2014) Ultraprocessed food products and obesity in Brazilian households (2008-2009). PLoS One 9, e92752.

47. Pan American Health Organization (2015) Ultra-processed Food and Drink Products in Latin America: Trends, Impact on Obesity, Policy Implications. Washington, DC: PAHO.

48. Martins APB, Levy RB, Claro RM et al. (2013) Increased contribution of ultra-processed food products in the Brazilian diet (1987-2009). Rev Saude Publica 47, 656-665.

49. Tavares LF, Fonseca SC, Garcia Rosa ML et al. (2012) Relationship between ultra-processed foods and metabolic syndrome in adolescents from a Brazilian Family Doctor Program. Public Health Nutr 15, 82-87.

50. Juul F \& Hemmingsson E (2015) Trends in consumption of ultra-processed foods and obesity in Sweden between 1960 and 2010. Public Health Nutr 18, 3096-3107.

51. Moreira PVL, Baraldi LG, Moubarac J-C et al. (2015) Comparing different policy scenarios to reduce the consumption of ultra-processed foods in UK: impact on cardiovascular disease mortality using a modelling approach. PLoS One 10, $\mathrm{e} 0118353$.

52. Moubarac J-C \& Batal M (2016) La consommation d'aliments transformés et la qualité de l'alimentation au Québec. Rapport soumis au Ministère de la Santé et des Services sociaux du Québec (MSSS). Montréal, QC: Université de Montréal (in French). 
53. Louzada ML, Baraldi LG, Steele EM et al. (2015) Consumption of ultra-processed foods and obesity in Brazilian adolescents and adults. Prev Med 81, 9-15.

54. Boggs DA, Rosenberg L, Rodriguez-Bernal CL et al. (2013) Long-term diet quality is associated with lower obesity risk in young African American women with normal BMI at baseline. J Nutr 143, 1636-1641.

55. Varraso R, Chiuve SE, Fung TT et al. (2015) Alternate Healthy Eating Index 2010 and risk of chronic obstructive pulmonary disease among US women and men: prospective study. BMJ 350, h286.

56. Wang DD, Leung CW, Li Y et al. (2014) Trends in dietary quality among adults in the United States, 1999 through 2010. JAMA Intern Med 174, 1587-1595.

57. Bergeron O, Richer F, Bruneau S et al. (2015) The Diet of Québec First Nations and Inuit Peoples. Québec, QC: Institut national de santé publique du Québec.

58. Torrie J, Bobet E, Kishchuk N et al. (2005) The Evolution of Health Status and Health Determinants in the Cree Region (Eeyou Istchee). Eastmain 1-A Powerhouse and Rupert
Diversion Sectoral Report. Volume 2: Detailed Analysis. Chisasibi, QC: Cree Board of Health \& Social Services of James Bay.

59. Earle L (2011) Traditional Aboriginal Diets and Health. Prince George, BC: National Collaborating Centre for Aboriginal Health.

60. Shim J-S, Oh K \& Kim HC (2014) Dietary assessment methods in epidemiologic studies. Epidemiol Health 36, e2014009.

61. Willett W (2013) Nutritional Epidemiology, 3rd ed. Oxford/ New York: Oxford University Press.

62. Moshfegh AJ, Rhodes DG, Baer DJ et al. (2008) The US Department of Agriculture Automated Multiple-Pass Method reduces bias in the collection of energy intakes. Am J Clin Nutr 88, 324-332.

63. Conway JM, Ingwersen LA, Vinyard BT et al. (2003) Effectiveness of the US Department of Agriculture 5-step multiple-pass method in assessing food intake in obese and nonobese women. Am J Clin Nutr 77, 1171-1178.

\section{Appendix}

Dietary intake by aHEI-2010 score quintiles of Eeyou adults ( $\geq 18$ years old) from seven northern Québec communities, Canada, 2005-2009 Aschii Nituuchischaayihititaau Environment-and-Health Study

\begin{tabular}{|c|c|c|c|c|c|c|c|c|c|c|}
\hline & \multicolumn{10}{|c|}{ Quintiles of aHEl-2010 score } \\
\hline & \multicolumn{2}{|c|}{$\begin{array}{c}\text { Q1 } \\
(n 162)\end{array}$} & \multicolumn{2}{|c|}{$\begin{array}{c}\mathrm{Q} 2 \\
(n 162)\end{array}$} & \multicolumn{2}{|c|}{$\begin{array}{c}\text { Q3 } \\
(n 163)\end{array}$} & \multicolumn{2}{|c|}{$\begin{array}{c}\mathrm{Q} 4 \\
(n 162)\end{array}$} & \multicolumn{2}{|c|}{$\begin{array}{c}\mathrm{Q} 5 \\
(n 162)\end{array}$} \\
\hline & Mean & SD & Mean & SD & Mean & SD & Mean & SD & Mean & SD \\
\hline \multicolumn{11}{|l|}{ Dietary intake } \\
\hline Total energy intake (kJ/d) & 10732 & 4012 & 10138 & 4632 & 9740 & 4682 & 8418 & 3782 & 8364 & 4163 \\
\hline Total energy intake (kcal/d) & 2565 & 959 & 2423 & 1107 & 2328 & 1119 & 2012 & 904 & 1999 & 995 \\
\hline Protein intake $(\mathrm{g} / \mathrm{d})$ & $107 \cdot 0$ & $50 \cdot 2$ & $108 \cdot 0$ & $65 \cdot 1$ & $107 \cdot 0$ & $59 \cdot 7$ & $101 \cdot 0$ & $60 \cdot 2$ & $112 \cdot 0$ & $66 \cdot 7$ \\
\hline Dietary fat intake $(\mathrm{g} / \mathrm{d})$ & $108 \cdot 0$ & $51 \cdot 8$ & $104 \cdot 0$ & $56 \cdot 7$ & 94.9 & $56 \cdot 7$ & 85.8 & $51 \cdot 0$ & $87 \cdot 2$ & $54 \cdot 8$ \\
\hline Carbohydrate intake $(\mathrm{g} / \mathrm{d})$ & 285 & 112 & 263 & 132 & 253 & 133 & 206 & 102 & 186 & 109 \\
\hline \multicolumn{11}{|l|}{ aHEI-2010 items } \\
\hline Fruit (servings/d) & 0.21 & 0.41 & 0.51 & $1 \cdot 20$ & 0.46 & 0.96 & 0.44 & 0.99 & 0.85 & 1.47 \\
\hline Vegetables (servings/d) & 0.59 & 1.25 & 0.49 & 0.91 & 0.77 & 1.06 & 0.70 & $1 \cdot 12$ & 0.66 & 1.39 \\
\hline Whole grains $(\mathrm{g} / \mathrm{d})$ & 0.46 & 1.29 & 0.56 & 1.52 & $0 \cdot 70$ & $2 \cdot 32$ & 0.52 & $1 \cdot 88$ & 0.54 & 1.26 \\
\hline SSB and fruit juice (servings/d) & 3.51 & $2 \cdot 57$ & 2.97 & 2.56 & 2.49 & $2 \cdot 61$ & 1.88 & $2 \cdot 03$ & 0.63 & 1.49 \\
\hline Nuts and legumes (servings/d) & 0.01 & 0.07 & 0.05 & 0.27 & 0.09 & 0.26 & $0 \cdot 10$ & 0.45 & 1.50 & $9 \cdot 26$ \\
\hline Red/processed meat (servings/d) & 0.59 & 1.72 & $2 \cdot 34$ & $3 \cdot 22$ & 3.65 & $4 \cdot 12$ & $6 \cdot 35$ & 4.07 & 8.02 & 3.08 \\
\hline Trans-fatty acids (\%E) & 0.014 & 0.014 & 0.010 & 0.009 & 0.009 & 0.012 & 0.008 & 0.009 & 0.006 & 0.006 \\
\hline $\mathrm{LC} n-3$ fatty acids $(\mathrm{EPA}+\mathrm{DHA} ; \mathrm{mg} / \mathrm{d})$ & 0.05 & 0.18 & 0.16 & 0.58 & 0.23 & 0.66 & 0.33 & 0.97 & 1.03 & 2.60 \\
\hline PUFA (\%E) & 5.83 & $2 \cdot 22$ & $7 \cdot 13$ & 2.53 & 6.97 & 3.05 & 7.97 & 3.19 & 8.61 & 3.62 \\
\hline Sodium $(\mathrm{mg} / \mathrm{d})$ & 4120 & 1988 & 3564 & 1694 & 3062 & 1713 & 2636 & 1617 & 2138 & 1364 \\
\hline Alcohol (drinks/d) & 0.024 & 0.182 & 0.016 & 0.112 & 0.031 & 0.174 & 0.015 & 0.096 & 0.018 & 0.113 \\
\hline
\end{tabular}

aHEI-2010, alternative Healthy Eating Index 2010; SSB, sugar-sweetened beverages; LC, long chain; \%E, percentage of energy. 